\title{
The Claim of Anti-Cataract Potential of Heliotropium indicum: A Myth or Reality?
}

\author{
Samuel Kyei · George Asumeng Koffuor · Paul Ramkissoon • \\ Clement Afari · Emmanuel Akomanin Asiamah
}

To view enhanced content go to www.ophthalmology-open.com

Received: September 25, 2015 / Published online: November 23, 2015

(C) The Author(s) 2015. This article is published with open access at Springerlink.com

\section{ABSTRACT}

Introduction: Heliotropium indicum has several uses in traditional medicine attributable to its numerous bioactive compounds. It is used as a traditional remedy for cataracts in Ghana without any scientific verification. This study aimed at verifying the anti-cataract properties of an aqueous whole plant extract of $H$. indicum.

S. Kyei $(\bowtie)$ · G. A. Koffuor · P. Ramkissoon Discipline of Optometry, School of Health Sciences, College of Health Sciences, University of KwaZulu-Natal, Durban, South Africa e-mail: skyei@ucc.edu.gh

S. Kyei

Department of Optometry, School of Allied Health Sciences, College Health and Allied Sciences, University of Cape Coast, Cape Coast, Ghana

\section{G. A. Koffuor}

Department of Pharmacology, Faculty of Pharmacy and Pharmaceutical Sciences, Kwame Nkrumah University of Science and Technology, Kumasi, Ghana

C. Afari

Department of Optometry and Visual Sciences, College of Science, Kwame Nkrumah University of Science and Technology, Kumasi, Ghana

\section{E. A. Asiamah}

Department of Pathology, Komfo Anokye Teaching Hospital, Kumasi, Ghana
Methods: The effect (cataract score) of 30, 100, and $300 \mathrm{mg} \mathrm{kg}^{-1}$ extract (bid for 21 days, per os) on the development of $30 \mu \mathrm{mol} \mathrm{kg} \mathrm{kg}^{-1}$ sodium selenite-induced cataract in 10-day-old rat pups was investigated. Soluble lens proteins alpha A and alpha B crystallins, total lens protein, total lens glutathione, and aquaporin 0 in enucleated lens homogenates were determined spectrophotometrically using commercially available kits. Histopathological studies on the lenses were also performed. The 2,2-diphenyl-1-picrylhydrazyl scavenging effect and linoleic acid autoxidation (antioxidant properties) of the extract $\left(0.1-3.0 \mathrm{mg} \mathrm{ml}^{-1}\right)$, compared to $n$-propyl gallate, were ascertained using standard procedures.

Results: Cataract scores showed that the extract, at all dose levels, significantly alleviated selenite-induced cataracts $(P \leq 0.001)$. Markers of lens transparency (aquaporin 0, alpha A and B crystallins), as well as total lens proteins and lens glutathione levels, were significantly preserved $(P \leq 0.01-0.001)$. The extract exhibited activity relevant for scavenging free radicals and inhibition of lipid peroxidation. Epithelial and lens fiber integrity in the histopathological 
assessment were maintained with HIE treatment.

Conclusion: The aqueous whole plant extract of $H$. indicum significantly inhibited the development of cataracts in rats via multiple mechanisms.

Keywords: Alpha A and alpha B crystallins; Aquaporin 0; Cataract; DPPH scavenging effect

\section{INTRODUCTION}

Heliotropium indicum (Family: Boraginaceae) has long been used in traditional medicine for the treatment of several ailments not only in Ghana but also in several other parts of the globe [1]. Its medicinal prowess has led to several scientific investigations into its pharmacological activity and the isolation of several alkaloids of pharmacological importance. Notable among these alkaloids are indicine, indicine- $\mathrm{N}$-oxide, acetyl-indicine, indicinine, heleurine, heliotrine, supinine, supinidine, and lindelofidine [2-7]. Some of these bioactive compounds, such as indicine- $N$-oxide, have gained attention for their anti-cancer properties despite safety concerns [6].

With the advances made in investigating $H$. indicum's bioactivity in managing various systems disorders, its traditional uses as an antidote for ocular disorders such as conjunctivitis, uveitis, and cataract remain largely unverified $[8,9]$.

Against the backdrop that cataracts remain the leading cause of blindness in the world, and the number one cause of ocular morbidity among the elderly with limited management options (only surgery is approved), claims and unverified reports of potential anti-cataract agents deserve attention [10, 11]. This search for alternative treatment for chronic disorders such as cataracts has rejuvenated scientists' interest in plant medicine as a possible source of remedy, some of which have made their way into mainstream allopathic medicine. Examples of these plant-derived medications include atropine, muscarine, and physostigmine [12]. However, amidst all these developments, plant-based pharmaceuticals are still largely untapped. Of the estimated 250,000-500,000 plant species, only a small percentage have been investigated phytochemically and an even smaller percentage have been well studied regarding their pharmacological action [13]. This highlights the need for rigorous scientific research into the botanicals used in traditional medicine as a basis for developing novel medication to cater for unmet medical needs.

Based on this assertion, this study sought to conduct an initial investigation aimed at examining the anti-cataract claims of $H$. indicum commonly used either orally (whole plant) or topically (leaves) by some Ghanaian people to ascertain the veracity of this claim.

\section{METHODS}

\section{Plant Collection}

Heliotropium indicum was collected from the botanical gardens of the University of Cape Coast $\left(5.1036^{\circ} \mathrm{N}, 1.2825^{\circ} \mathrm{W}\right)$, Cape Coast, in the Central Region of Ghana, in November 2012. It was identified and authenticated by a botanist at the University of Cape Coast herbarium, where a voucher specimen bearing the number 4873 has been deposited for future reference.

\section{Preparation of the Aqueous Whole Plant Extract of $\boldsymbol{H}$. indicum}

Whole plants of $H$. indicum were washed thoroughly with tap water and shade dried. 
The dry plants were milled into a coarse powder by a hammer mill (Schutte Buffalo, New York, NY, USA). One and a half kilograms of the plant powder was mixed with one liter of water. The mixture was Soxhlet extracted at $80^{\circ} \mathrm{C}$ for $24 \mathrm{~h}$. The aqueous extract obtained was freeze-dried (Hull freeze-dryer/lyophilizer 140 SQ, Warminster, PA, USA). The powder (yield $12.2 \%)$, labeled as whole plant extract of $H$. indicum (HIE), was stored at $4{ }^{\circ} \mathrm{C}$ and reconstituted in normal saline to the desired concentration for dosing in this study.

\section{Drugs and Chemicals}

Sodium selenite, $\mathrm{Na}_{2} \mathrm{SeO}_{3}$ (Sigma Aldrich, Germany), was used to induce cataracts. Tropicamide 1\% ophthalmic solution [Alcon Laboratories South Africa (Pty) Ltd] was used to dilate the pupil of the eye at every slit-lamp examination.

\section{2,2-Diphenyl-1-picrylhydrazyl(DPPH),}

methanol, ethanol, sodium phosphate, $n$-propyl gallate, linoleic acid $(\mathrm{BDH}$, Poole, UK), trichloroacetic acid, and thiobarbituric acid (Sigma-Aldrich, St. Louis, MO, USA) were used in the antioxidant assays.

\section{Animals and Husbandry}

Ten-day-old Sprague-Dawley rat pups of either sex (mean weight of $24 \pm 2 \mathrm{~g}$ ) were kept in the Animal House of the School of Biological Sciences, University of Cape Coast. The pups (and their mothers) were housed in polyacrylic cages $(34 \times 47 \times 18 \mathrm{~cm})$ with soft wood shavings as bedding, under ambient laboratory conditions (temperature $28 \pm 2{ }^{\circ} \mathrm{C}$, relative humidity $60-70 \%$, and a normal light-dark cycle). The mothers were fed on a normal commercial pellet diet (Agricare Ltd., Kumasi, Ghana) and had access to water ad libitum.

\section{Ethical and Biosafety Considerations}

The study protocol was approved by the Institutional Review Board on Animal Experimentation, Faculty of Pharmacy and Pharmaceutical Sciences, Kwame Nkrumah University of Science and Technology, Kumasi, Ghana (Ethical Clearance Number: FPPS/PCOL/ 0030/2013). All activities performed during the studies conformed to accepted principles for laboratory animal use and care (EU directive of 1986: 86/609/EEC) and Association for Research in Vision and Ophthalmology Statement for Use of Animals in Ophthalmic and Vision research. Biosafety guidelines for the protection of personnel in the laboratory were observed.

\section{Preliminary Phytochemical Screening}

Screening was performed on HIE to ascertain the presence of phytochemicals using standard procedures described by Harborne [14] and Kujur et al. [15].

\section{Effect of HIE on Selenite-Induction of Cataract in Pups}

Ten-day-old rat pups were injected subcutaneously with $15 \mu \mathrm{mol} \mathrm{kg}^{-1}$ sodium selenite in normal saline daily for 2 days. The pups were then put into four groups $(n=8$, i.e., the number of rats per group). Groups I-IV received 30, 100, $300 \mathrm{mg} \mathrm{kg}^{-1}$ HIE, and $10 \mathrm{~mL} \mathrm{~kg}^{-1}$ normal saline, respectively, per os, $30 \mathrm{~min}$ after the first selenite injection. These doses were used based on preliminary studies to establish activity in our laboratory. Treatment was then given twice daily ( $12 \mathrm{~h}$ ) for 21 days. A fifth group (V) made up of normal pups given no selenite injection nor treatment was also kept under same experimental conditions as a 
normal control. On day 21 after selenite injection, the pupils of the pups' eyes were dilated using $1 \%$ tropicamide ophthalmic solution and assessment of the crystalline lens for developing cataract made using a Marco II-B Slit Lamp (Marco-Lombart Instrument, Japan). The developing cataracts were then graded and scored after repeating the experiment on three different occasions.

\section{Grading and Scoring of Cataract}

Two researchers (SK and $\mathrm{CAH}$ ) individually graded the lens opacification (masked and in a random order) as in Table 1 . The grades were then scored and expressed as the percentage of total lenses in each group using the following formula:

$$
\begin{aligned}
& \% \text { cataract } \\
& =\frac{\text { number of cataractous eyes per group }}{\text { total number of eyes per group }} \times 100
\end{aligned}
$$

\section{Determination of Lens Glutathione}

The total glutathione (GSH) in the crystalline lens was determined using a commercially acquired kit (Cayman Chemicals, Ann Arbor, MI, USA). The lenses from the enucleated eye of the rats were rinsed with phosphate-buffered saline (PBS), $\mathrm{pH} 7.4$, to remove any blood clots. They were then homogenized in $5 \mathrm{~mL}$ of $50 \mathrm{mM}$ MES (2-( $N$-morpholino) ethanesulfonic acid,
pH 7), using Precellys 24 tissue homogenizer (Bertin Technologies, France). The lens homogenate was centrifuged at $100,000 \mathrm{~g}$ for $15 \mathrm{~min}$ at a temperature of $4{ }^{\circ} \mathrm{C}$, after which the supernatant was deproteinated using metaphosphoric acid and $4 \mathrm{M}$ triethanolamine according to the manufacturer's instructions. A $50 \mu \mathrm{L}$ volume of the deproteinated lens samples and the standards (constituted per the manufacturer's directive) were pipetted into a 96-well microtiter plate and read at $405 \mathrm{~nm}$ with a URIT-660 microplate reader (URIT Medical Electronic Co., Ltd, Guangxi, China) after incubation in the dark on an orbital shaker for $30 \mathrm{~min}$. Each determination was done in triplicate.

\section{Determination of Total Lens Protein Concentration}

A bicinchoninic acid (BCA) protein assay kit (Pierce, Rockford, IL, USA) was used to establish the total protein concentration in the lens homogenate obtained from the enucleated rat eyes. For total protein estimation, the lens homogenate was prepared in 5\% trichloroacetic acid. The precipitated protein was dissolved in 5\% sodium hydroxide and used as aliquots for the estimation of total proteins. The protein concentration was determined by pipetting $50 \mu \mathrm{L}$ of lens homogenate from: rats treated with 30,100 , and $300 \mathrm{mg} \mathrm{kg}^{-1}$ of HIE,

Table 1 Grading and scoring of selenite-induced cataract in lenses of Sprague-Dawley rats

\begin{tabular}{llr}
\hline Grade & Description & Score \\
\hline & Clear lens & 0 \\
I & Swollen lens fibers and subcapsular opacities & 1 \\
II & Nuclear cataract was observed in the lens but swollen fibers were still visible in the lens cortex & 2 \\
III & Strong nuclear cataract with peri-nuclear area opacity in the lens & 3 \\
IV & Total opacity of the lens & 4 \\
\hline
\end{tabular}


and $10 \mathrm{~mL} \mathrm{~kg}^{-1}$ normal saline; normal rats without selenite injection; and standard bovine serum albumin (BSA) into a 96-well microplate. A $200 \mu \mathrm{L}$ volume of working reagent, constituted according to the manufacturer's instructions, was mixed thoroughly with the content of each well and shaken for $30 \mathrm{~s}$. It was then incubated at $37^{\circ} \mathrm{C}$ for $30 \mathrm{~min}$ and allowed to cool to room temperature. Absorbances of the mixtures were measured at $562 \mathrm{~nm}$ using an URIT-660 microplate reader. Each determination was done in triplicate.

\section{Determination of Soluble Lens Protein}

Soluble lens proteins were determined using a commercially available ELISA kits (MyBioSource, Inc., San Diego, CA, USA). Soluble lens protein levels, mainly alpha A (CRYAA) and alpha B (CRYAB), were estimated after the lens tissue was rinsed with PBS, homogenized in $1 \mathrm{~mL}$ of $1 \mathrm{X}$ PBS, and stored overnight at $-20{ }^{\circ} \mathrm{C}$. After two freeze-thaw cycles were performed to break the cell membranes, the homogenates were centrifuged for $5 \mathrm{~min}$ at $5000 \mathrm{~g}$ and $2-8{ }^{\circ} \mathrm{C}$. The supernatant was removed and assayed immediately. A $100 \mu \mathrm{L}$ of standard and sample per well was constituted, covered with an adhesive strip, and incubated for $2 \mathrm{~h}$ at $37^{\circ} \mathrm{C}$. Several other intermittent incubations were done in accordance with the manufacturer's instructions. Absorbances of the mixtures were measured at $450 \mathrm{~nm}$ using a URIT-660 microplate reader. Each determination was done in duplicate.

\section{Determination of Aquaporin 0}

A commercial kit which uses a double-antibody sandwich enzyme-linked immunosorbent one-step process assay (ELISA; MyBioSource, Inc., MBS 028997) was used to assay the level of aquaporin 0 (AQP0) in lens homogenate samples. Standard, test sample, and HRP-labeled AQP0 antibodies were pipetted into the enzyme wells which are pre-coated with AQP0 antibody. These were then incubated (at $37^{\circ} \mathrm{C}$ in the dark at different time periods as specified by the manufacturer) and washed manually with de-ionized water using a Pasteur pipette to remove the uncombined enzyme. Upon adding Chromogen Solution A and B, the color of the liquid changed to blue and finally to yellow after adding the stop solution. The optical density (OD) was then measured at $450 \mathrm{~nm}$ using a URIT-660 microplate reader. Based on the concentration standards and their corresponding OD values, a standard curve linear regression equation was computed. From this curve, the OD values of the sample on the regression equation were used to calculate the corresponding sample's concentration.

\section{Histopathological Assessment}

The extracted lenses from enucleated eyes of the animals were fixed in 10\% phosphate-buffered paraformaldehyde and embedded in paraffin. Sections were made and stained with hematoxylin and eosin [16], and fixed on glass slides for microscopic examination at the Department of Biomedical and Forensic science, University of Cape Coast, Cape Coast, for histopathological assessment by an experimental pathologist.

\section{Antioxidant Property of HIE}

\section{Free Radical Scavenging Assay}

This procedure was performed as previously described by Govindarajan et al. [17] with few modifications. Concentrations of 
0.1-3.0 $\mathrm{mg} \mathrm{mL}^{-1}$ HIE in $99.8 \%$ methanol were selected and compared with $0.001-0.03 \mathrm{mg} \mathrm{mL}^{-1} \quad n$-propyl gallate in methanol (reference free radical scavenger). HIE was centrifuged at $3000 \mathrm{~g}$ for $10 \mathrm{~min}$. One milliliter of the supernatant was added to $3 \mathrm{~mL}$ of a $20 \mathrm{mg} \mathrm{L}^{-1}$ methanolic DPPH solution and kept at $25^{\circ} \mathrm{C}$ for $1 \mathrm{~h}$ in an orbital shaker (BoroLabs, Aldermaston, Berkshire, UK). A $1 \mathrm{~mL}$ quantity of $99.8 \%$ methanol (control) was added to $3 \mathrm{~mL}$ DPPH solution and incubated under the same conditions. The absorbance of the residual DPPH was determined at $517 \mathrm{~nm}$ in a Cecil CE 2040 spectrophotometer (Cecil Instruments Limited, Cambridge, UK). Methanol was used as the blank. The procedure was done in triplicate and the results expressed as percentage DPPH scavenging effect against concentration. The half maximal inhibitory concentration $\left(\mathrm{IC}_{50}\right)$ values were established.

\section{Linoleic Acid Autoxidation}

The method previously described by Mitsuda et al. [18] was used. Concentrations of 0.1-3.0 $\mathrm{mg} \mathrm{mL}^{-1}$ HIE in $96 \%$ ethanol were compared with $0.001-0.03 \mathrm{mg} \mathrm{ml}^{-1} n$-propyl gallate (reference antioxidant) in 96\% ethanol. Two milliliter quantities each of the ethanolic HIE and $n$-propyl gallate mixtures were put into separate screw cap test tubes. $2.05 \mathrm{~mL}$ of $2.51 \%$ linoleic acid (in $96 \%$ ethanol), $4 \mathrm{~mL}$ of $0.05 \mathrm{M}$ phosphate buffer (pH 7.0), and $1.9 \mathrm{~mL}$ of distilled water were then added to the test tube and placed in an oven at $40^{\circ} \mathrm{C}$ in the dark for 7 days. To $2 \mathrm{~mL}$ each of the HIE and the $n$-propyl gallate mixture prepared and incubated, $2 \mathrm{~mL}$ of $20 \%$ trichloroacetic acid (aq) solution and $1 \mathrm{~mL}$ of $0.6 \%$ thiobarbituric acid (aq) solution were added. The mixtures were placed in a boiling water bath for $10 \mathrm{~min}$, cooled, and centrifuged at $3000 \mathrm{~g}$ for $10 \mathrm{~min}$.
The absorbances of the supernatant were measured and the percentage inhibition of linoleic acid autoxidation was calculated using the following formula:

$\%$ inhibition $=\frac{\left(C_{0}-C_{1}\right)-\left(D-D_{0}-C_{0}\right)}{\left(C_{0}-C_{1}\right)} \times 100$

where $C_{0}$ (full reaction mixture) is the degree of lipid peroxidation in the absence of antioxidant; $C_{1}$ is the underlying lipid peroxidation before the initiation of lipid peroxidation; $D$ is any absorbance produced by the extract being tested; and $D_{0}$ is the absorbance of the extract alone.

\section{Statistical Analysis}

Statistical analysis of the data obtained was done using GraphPad Prism version 5.0 (GraphPad Software, Inc., La Jolla, CA, USA). Differences between treatment groups and the controls were estimated using one-way analysis of variance (ANOVA) followed by Dunnet's multiple comparisons test (post hoc test) at a confidence level of $95 \%$. Probability values $\leq 5 \%$ $(P \leq 0.05)$ were considered significant.

\section{RESULTS}

\section{Phytochemical Screening}

Preliminary phytochemistry showed that flavonoids, saponins, cyanogenic glycosides, sterol, tannins, and alkaloids were present in HIE (Table 2).

\section{Effect of HIE on Selenite-Induced Cataracts}

Slit-lamp assessment revealed that normal saline-treated pups had 10 of the 16 eyes 
(62.5\%) developed total cataract (grade IV), with the remaining $6(37.5 \%)$ having strong nuclear cataract (grade III). Meanwhile, only one $30 \mathrm{mg} \mathrm{kg}^{-1}$ HIE-treated rat (2 eyes, $12.5 \%$ ) had grade I cataracts, while the remaining 14 eyes $(87.5 \%)$ had clear lenses. HIE showed the greatest activity against selenite-induced cataracts at the highest dose of $300 \mathrm{mg} \mathrm{kg}^{-1}$ (i.e., none had cataracts). Nevertheless, the $100 \mathrm{mg} \mathrm{kg}^{-1}$ HIE-treated eyes had only 6 lenses out of the 16 without cataract (4 eyes had grade IV cataracts, 2 eyes had grade III cataracts, and 4 eyes had grade II cataracts). None of the normal control rats had cataracts (Fig. 1). The cataract scores showed that HIE at all dose levels significantly $(P \leq 0.001)$ alleviated cataracts induced with sodium selenite (Fig. 1).

\section{Effect of HIE on Lens GSH}

HIE activity against cataracts was supported by the significantly high levels of GSH in the HIE-treated eyes compared to the normal saline-treated eyes ( $P \leq 0.01-0.001$; Fig. 2$)$.

Table 2 Results obtained after preliminary phytochemical screening of HIE

\begin{tabular}{lc}
\hline Phytochemical & Present/absent \\
\hline Anthraquinones & - \\
Tannins & + \\
Flavonoids & + \\
Alkaloids & + \\
Sterols & + \\
Glycosides & + \\
Saponins & + \\
Triterpenoids & - \\
\hline
\end{tabular}

+ Present; - absent

\section{Total Lens Protein and Soluble Protein}

\section{Concentration}

Estimation of total lens protein and soluble lens protein was consistently indicative of the degree of lens transparency. There were significantly high concentrations of total protein, CRYAA, and CRYAB depending on the transparency of the lens $(P \leq 0.01-0.001$; Table 3).

\section{Aquaporin 0 Levels in the Lens}

The estimated levels of AQPO water channel, whose permeability is tightly regulated in healthy lenses, was significantly high indicating they were preserved when treated with the extract $(P \leq 0.001$; Fig. 3$)$.

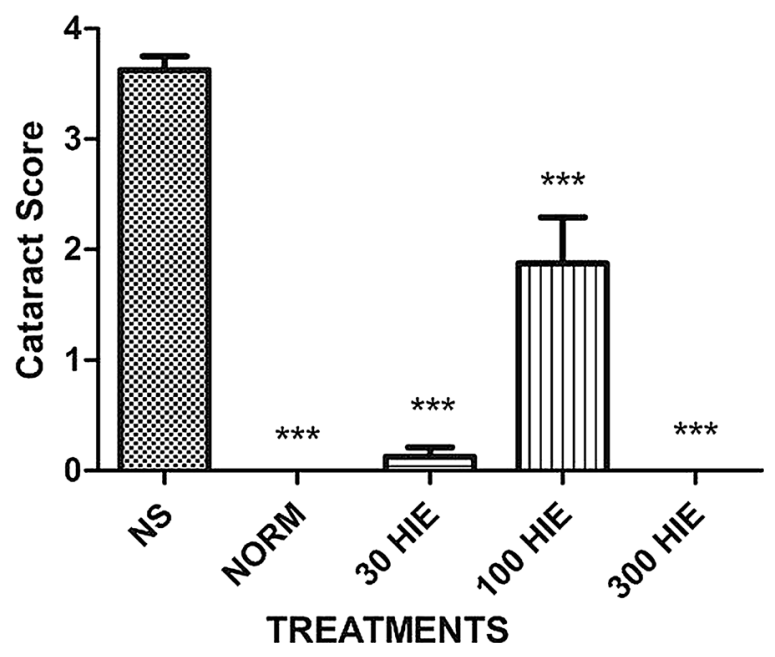

Fig. 1 The effects of 30,100 , and $300 \mathrm{mg} \mathrm{kg}^{-1} \mathrm{HIE}$, and $10 \mathrm{~mL} \mathrm{~kg}^{-1} \mathrm{NS}$ on selenite-induced cataractous in Sprague-Dawley rats. Values plotted are mean \pm standard error of the mean $(n=8)$. ${ }^{* * *} P \leq 0.001$; ANOVA followed by Dunnett's post hoc test. NORM normal control, NS normal saline, HIE whole plant extract of Heliotropium indicum 


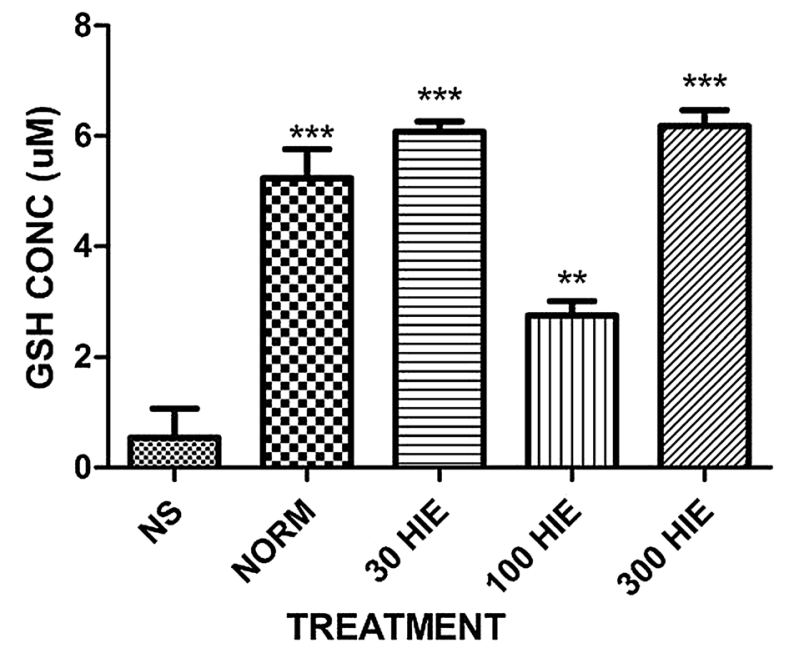

Fig. 2 The effects of 30,100 , and $300 \mathrm{mg} \mathrm{kg}^{-1}$ of HIE, and $10 \mathrm{~mL} \mathrm{~kg}^{-1} \mathrm{NS}$ on GSH levels in selenite-induced cataractous Sprague-Dawley rats. Values plotted are mean \pm standard error of the mean $(n=8) .{ }^{* *} P \leq 0.01$; ${ }^{* * *} P \leq 0.001$; ANOVA followed by Dunnett's post hoc test. GSH glutathione, NORM normal control, NS normal saline, HIE whole plant extract of Heliotropium indicum

\section{Free Radical Scavenging Effect} and Linoleic Acid Autoxidation Assay

HIE showed a concentration-dependent scavenging activity in a similar manner to $n$-propyl gallate. The $\mathrm{IC}_{50}$ values obtained for HIE and $n$-propyl gallate were 5.85 and $1.12 \mathrm{mg} \mathrm{ml}^{-1}$, respectively (Fig. 4). Both $n$-propyl gallate and HIE showed concentration-dependent inhibition of linoleic acid autoxidation with $\mathrm{IC}_{50}$ values of 1.02 and $2.78 \mathrm{mg} \mathrm{ml}^{-1}$, respectively (Fig. 5).

\section{Histopathological Assessment}

The histopathological assessment showed that the integrity of the lens epithelium (which is instrumental in lens homeostasis) was preserved, and, at the same time, the architecture of the lens fibers in all HIE-treated rats and normal rats was also maintained. However, there was observable epithelial erosion of the lens and abnormal morphology of the lens fibers (Fig. 6).

\section{DISCUSSION}

Selenite-induced cataract is a common model of senile cataract employed in preclinical studies for screening potential anti-cataract agents [19]. Overdose of this salt has been hypothesized to cause cataracts by a series of processes which includes: alteration of epithelial cell metabolism [20], enhanced oxidative stress [21], impairment of calcium homeostasis [22-24], apoptosis [25, 26], DNA damage [27], activation of m-calpain [28], and

Table 3 Total lens protein and soluble protein levels of controls and HIE-treated cataractous Sprague-Dawley rats

\begin{tabular}{llll}
\hline Treatment & \multicolumn{2}{l}{ Lens proteins } & \\
\cline { 2 - 4 } & Total protein $\left(\boldsymbol{\mu g} \mathbf{~ m L}^{-\mathbf{1}}\right)$ & CRYAA $\left(\mathbf{p g ~} \mathbf{~ L L}^{-\mathbf{1}}\right)$ & CRYAB $\left(\mathbf{p g ~} \mathbf{~ m L}^{-\mathbf{1}}\right)$ \\
\hline $10 \mathrm{~mL} \mathrm{~kg}^{-1} \mathrm{NS}$ & $2135 \pm 158.0$ & $167.3 \pm 13.14$ & $84.30 \pm 3.303$ \\
$\mathrm{NORM}$ & $4369 \pm 108.1^{* * *}$ & $673.2 \pm 43.09^{* * *}$ & $153.7 \pm 3.303^{* * *}$ \\
$30 \mathrm{mg} \mathrm{kg}^{-1} \mathrm{HIE}$ & $3500 \pm 39.67^{* * *}$ & $515.5 \pm 34.77^{* * *}$ & $153.7 \pm 3.303^{* * *}$ \\
$100 \mathrm{mg} \mathrm{kg}^{-1} \mathrm{HIE}$ & $2915 \pm 167.0^{* *}$ & $331.6 \pm 22.76^{* *}$ & $117.3 \pm 8.739^{* *}$ \\
$300 \mathrm{mg} \mathrm{kg}^{1} \mathrm{HIE}$ & $3545 \pm 83.48^{* * *}$ & $719.2 \pm 6.571^{* * *}$ & $160.3 \pm 5.721^{* * *}$ \\
\hline
\end{tabular}

Values are mean $\pm \operatorname{SEM}(n=8) .{ }^{* *} P \leq 0.01 ;{ }^{* * *} P \leq 0.001$; ANOVA followed by Dunnett's post hoc test $C R Y A A$ alpha crystallin A, CRYAB alpha crystallin B, NS normal saline, NORM normal control 


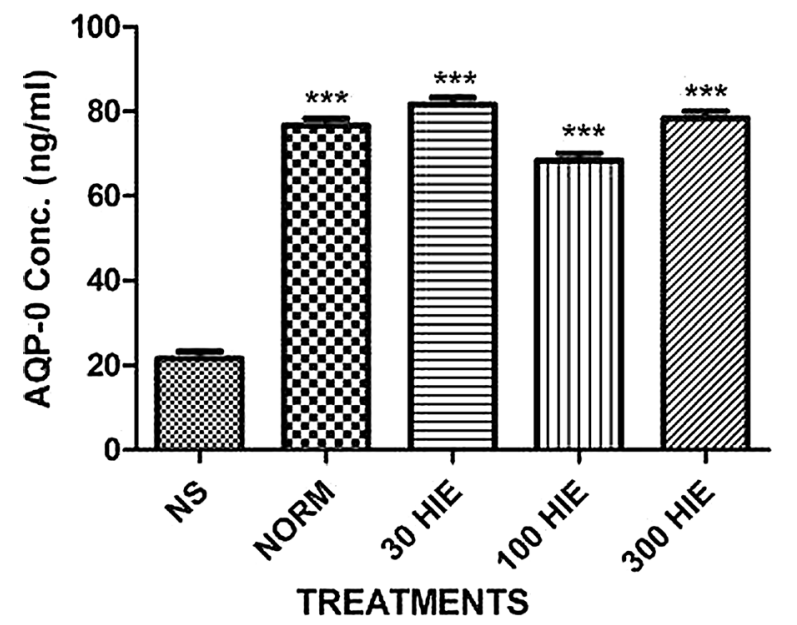

Fig. 3 The effects of 30,100 , and $300 \mathrm{mg} \mathrm{kg}^{-1} \mathrm{HIE}$, and $10 \mathrm{~mL} \mathrm{~kg}^{-1} \mathrm{NS}$ on AQP0 levels in selenite-induced cataractous Sprague-Dawley rats. Values plotted are mean \pm standard error of the mean $(n=8)$. ${ }^{* * *} P \leq 0.001$; ANOVA followed by Dunnett's post hoc test. AQPO aquaporin 0, NORM normal control, NS normal saline, HIE whole plant extract of Heliotropium indicum

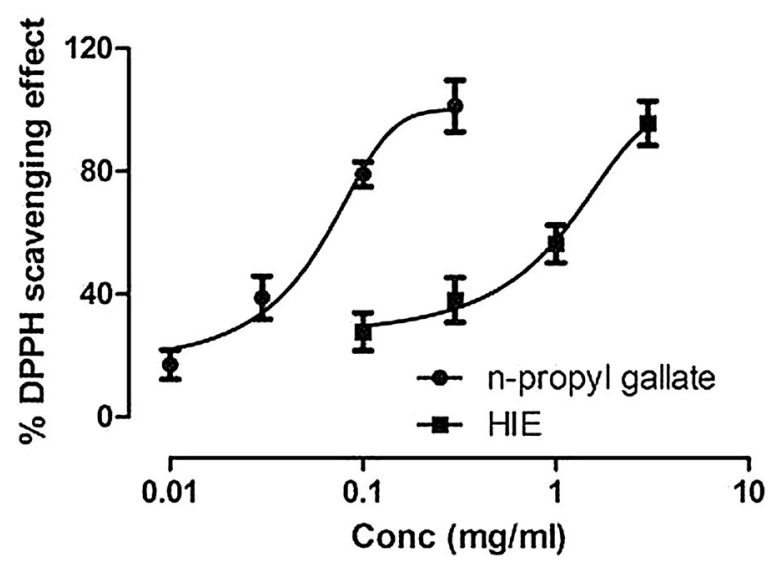

Fig. 4 Free radical scavenging ability of $n$-propyl gallate (0.001-0.03 $\mathrm{mg} \mathrm{mL}^{-1}$ ) and HIE $\left(0.1-3 \mathrm{mg} \mathrm{mL}^{-1}\right)$ in a $\mathrm{DPPH}$ free radical assay. Values plotted are mean \pm standard error of the mean $(n=3)$. DPPH 2,2-diphenyl-1-picrylhydrazyl, HIE whole plant extract of Heliotropium indicum

insolubilization of proteolyzed $\beta-$ and a-crystallins [29].

Although the $100 \mathrm{mg} \mathrm{kg}^{-1}$ HIE dose showed a slight drop in activity relative to the 30 and $300 \mathrm{mg} \mathrm{kg}^{-1}$ doses, its observed clinical effect is

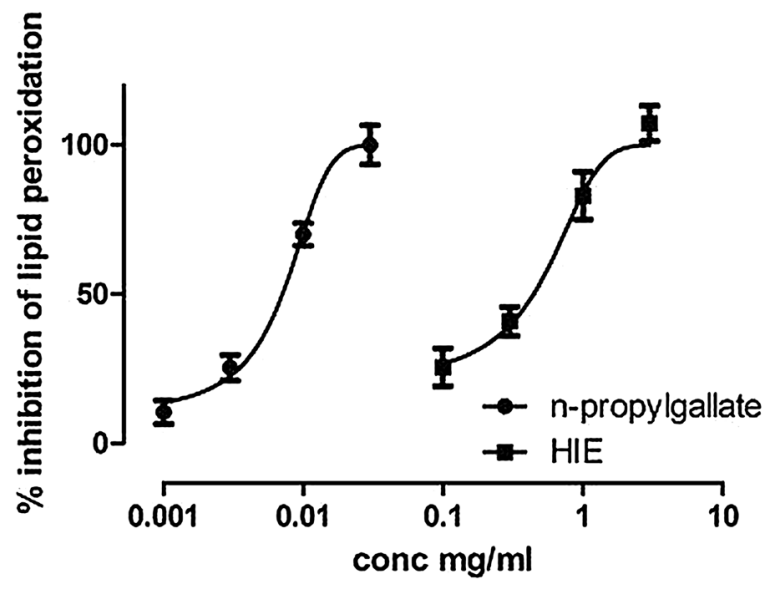

Fig. 5 Percentage inhibition of linoleic acid autoxidation by $n$-propyl gallate $\left(0.001-0.03 \mathrm{mg} \mathrm{mL}^{-1}\right)$ and HIE $\left(0.1-3 \mathrm{mg} \mathrm{mL}^{-1}\right)$. Values plotted are mean \pm standard error of the mean $(n=3)$. HIE whole plant extract of Heliotropium indicum

desirable since a delay in cataract formation is known to prevent severe visual disability that could affect the independence of most people affected [30]. It has been projected that a delay in cataract formation of approximately 10 years would lessen the burden of a visually disabling cataract by approximately 45\% [19]. Such a delay, as shown by $100 \mathrm{mg} \mathrm{kg}^{-1} \mathrm{HIE}$, has the potential to enhance the quality of life for most of the world's elderly population at risk of cataract, and to considerably moderate both the economic burden due to disability and surgery related to cataract after further studies regarding isolation, structural elucidation, and efficacy have been performed.

Safeguarding the lens from oxidative stress, and the consequent maintenance of transparency, is ensured by endogenous antioxidant systems that consist of non-enzymatic and enzymatic machinery. Human senile or experimental cataractogenesis is linked with a progressive decline in lenticular GSH [31, 32]. For that reason, it has been hypothesized that GSH plays a key role in maintaining lens physiology and transparency 

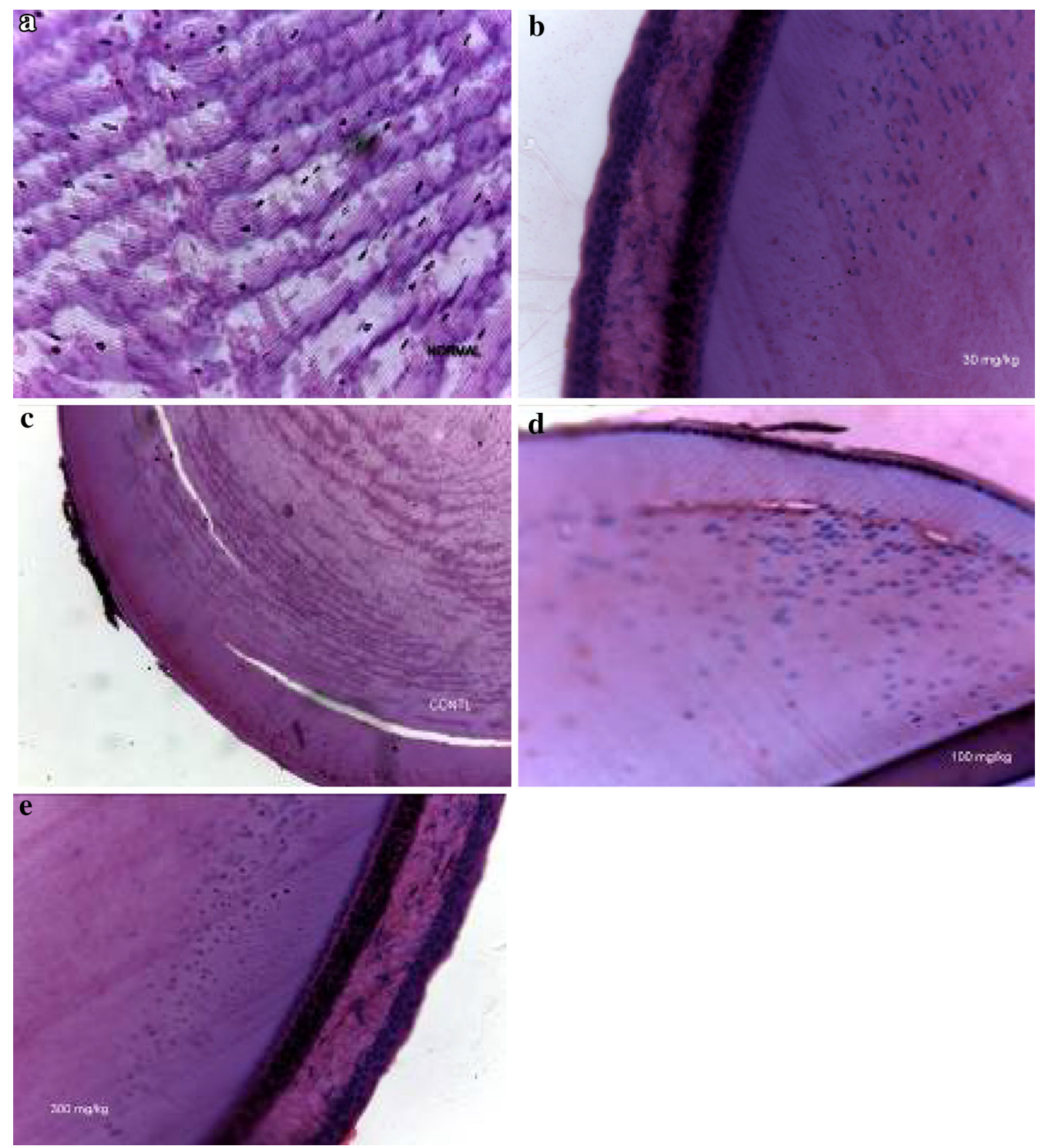

Fig. 6 Photomicrographs showing normal and selenite-induced cataractous rats treated with various doses of HIE or normal saline (control). a Normal lens showing regular arrangement of equatorial sections of outer lens cortex lens fiber interspersed with nuclei. b Selenite-induced cataractous lens with $30 \mathrm{mg} \mathrm{kg}^{-1} \mathrm{HIE}$ treatment showing intact cuboidal epithelium of the lens surface, normal subcapsular epithelial margin, and lens fiber nuclei. c Selenite-induced cataractous lens with $10 \mathrm{ml} \mathrm{kg}{ }^{-1}$ normal saline treatment

(control) showing a virtually eroded epithelial margin and distorted lens fiber morphology. d Selenite-induced cataractous lens with $100 \mathrm{mg} \mathrm{kg}^{-1}$ HIE treatment indicating a partially eroded epithelium and moderate mild changes in lens fiber morphology. e Selenite-induced cataractous lens with $300 \mathrm{mg} \mathrm{kg}^{-1}$ HIE treatment showing preserved cuboidal epithelium of the lens surface and normal subcapsular epithelial margin. HIE whole plant extract of Heliotropium indicum 
by protecting sulfhydryl groups from oxidation $[33,34]$. The acknowledged impact of oxidative damage in the pathology of cataracts, and in the aging process, has shifted attention to antioxidant therapy. Flavonoids and tannin in general have been proven to possess antioxidant activity relevant for scavenging free radicals and to inhibit lipid peroxidation [35-37].

The series of biochemical alterations that take place in selenite-induced cataractogenesis include the reduction of total soluble proteins of lens and loss of total protein concentration [38]. This presupposes that selenite-induced cataractogenesis affects the whole lens transport system. Selenite has again been reported to inhibit protein synthesis in test tube and human subjects after repeated exposures $[39,40]$. The conservation of the total protein concentration in the lens of the extract treated indicates that it is exerts it anti-cataract effect by preventing the inhibition of protein synthesis in the lens. Moreover, selenium salt (i.e., sodium selenite) causes a loss of $\alpha$-crystallins (a major protein component of the vertebrate eye lens) which have been found to exert a chaperone activity by binding to unfolded or denatured proteins and suppressing nonspecific aggregation [41]. This chaperone role helps to avert the development of large light-scattering aggregates, inactivation of oxidative enzymes, and probable cataractogenesis [42, 43]. The extract treatment preserved the $\alpha$-crystallin A and $\mathrm{B}$ in the right molar concentration of three to one [44]. This high concentration of total lens protein and water-soluble proteins in their right proportion is necessary for the maintenance of the optimum refractive index [45].

Gradual but persistent deterioration of lens tissue occurs as a pathophysiological consequence of malfunctioning water and nutrient exchange via channel and transporter proteins. These transporter proteins are crucial because of the avascular nature of the crystalline lens which may not survive on diffusion alone [46]. AQP0, also known as major intrinsic polypeptide (MIP), constitutes more than $60 \%$ of the total membrane protein content of fiber cells [47]. Aquaporins form channels for water permeability across biological membranes by high caliber 6-transmembrane helices that bring together a hydrophilic water-conducting pore [48]. AQP0 serves as a model to appreciate how water channels are regulated at the molecular level [48]. The preservation of the AQPO content of the lens via the extract treatment contributed to the maintenance of the lens transparency.

The possible mechanism of the anti-cataract effect of HIE is not definitive as there are multiple bioactive ingredients which may have either synergistic or antagonist effects depending on the dose. This possible interaction is predictive from the relative drop in effect of the $100 \mathrm{mg} \mathrm{kg}^{-1}$ to the other doses and deserves further investigation.

\section{CONCLUSIONS}

The aqueous extract of $H$. indicum has anti-cataract activity on selenite-induced cataracts in Sprague-Dawley rats and maybe useful as an anti-cataract agent for human cataracts after further studies.

\section{ACKNOWLEDGMENTS}

This study was partly funded by University of Cape Coast. We appreciate the technical assistance offered by Rex Ananne and Daniels Konja of the Department of Biomedical and 
Forensic Sciences, School of Biological Sciences, University of Cape Coast, Cape Coast, Ghana. This article results from research towards a Ph.D. (Optometry) degree in the Discipline of Optometry at the University of KwaZulu-Natal under the supervision of Dr. George A. Koffuor and co- supervision of Prof. Paul Ramkissoon. All named authors meet the International Committee of Medical Journal Editors (ICMJE) criteria for authorship for this manuscript, take responsibility for the integrity of the work as a whole, and have given final approval for the version to be published.

Disclosures. Samuel Kyei, George Asumeng Koffuor, Paul Ramkissoon, Clement Afari, and Emmanuel Akomanin Asiamah declare that they have no conflict of interest.

Compliance with ethics guidelines. The study protocol was approved by the Institutional Review Board on Animal Experimentation, Faculty of Pharmacy and Pharmaceutical Sciences, Kwame Nkrumah University of Science and Technology, Kumasi, Ghana (Ethical clearance number: FPPS/PCOL/ 0030/2013). All activities performed during the studies conformed to accepted principles for laboratory animal use and care (EU directive of 1986: 86/609/EEC) and Association for Research in Vision and Ophthalmology Statement for Use of Animals in Ophthalmic and Vision research. Biosafety guidelines for the protection of personnel in the laboratory were observed.

Open Access. This article is distributed under the terms of the Creative Commons Attribution-NonCommercial 4.0 International License (http://creativecommons.org/licenses/ by-nc/4.0/), which permits any noncommercial use, distribution, and reproduction in any medium, provided you give appropriate credit to the original author(s) and the source, provide a link to the Creative Commons license, and indicate if changes were made.

\section{REFERENCES}

1. Gurib-Fakim A. Heliotropium indicum L. In: Schmelzer GH, Gurib-Fakim A editors. Prota. 2006;11:(1) Medicinal plants/Plantes médicinales 1. [CD-Rom]. PROTA, Wageningen.

2. Pandey DP, Singh JP, Roy R, Singh VP, Pandey VB. Constituents of Heliotropium indicum. Orient J Chem. 1996;12:321-2.

3. Mattocks AR. Minor alkaloids of H. indicum. J Chem Soc. 1967;15:329-31.

4. Mattocks AR, Schoental R, Crowley HC, Culvenor CCJ. 1064. Indicine: the major alkaloid of Heliotropium indicum L. J Chem Soc. 1961;5400-5403.

5. Dutta SK, Sanyal U, Chakraborty SK. A modified method of isolation of Indicine- $\mathrm{N}$-Oxide from $H$. indicum and its antitumor activity against ehrlich ascites carcinoma and sarcoma-180. Indian J Cancer Chem. 1987;9:73-7.

6. Kugelman M, Liu WC, Axelrod M, Mc Bride TJ, Rao $\mathrm{KV}$. Indicine- $N$-oxide: the antitumor principle of Heliotropium indicum. Lloydia. 1976;39:125.

7. Birecka N, Frohlich MW, Glickman LM. Amino alcohols of pyrolizidine alkaloid in Heliotropium species. Part-4. Free and esterified necines in Heliotropium species from Mexico and Texas. Phytochemistry. 1983;22:1167-71.

8. Rahmatullah M, Das AK, Mollik M, Jahan R, Khan M, Rahman T, et al. An ethnomedicinal survey of Dhamrai sub-district in Dhaka District, Bangladesh. Am Eurasian J Sustain Agric. 2009;3:881-8.

9. Mollik MAH, Hossan MS, Paul AK, Rahman MT-U, Jahan R, Rahmatullah M. A comparative analysis of medicinal plants used by folk medicinal healers in three districts of Bangladesh and inquiry as to mode of selection of medicinal plants. Ethnobot Res Appl. 2010;8:195-218.

10. Baltussen R, Sylla M, Mariotti SP. Cost-effectiveness analysis of cataract surgery: a global and regional analysis. Bull World Health Organ. 2004;82:338-45.

11. Mariotti SP. Global data on visual impairments 2010. World Health Organization, 20 Avenue 
Appia, 1211 Geneva 27, Switzerland, 2012. WHO/ $\mathrm{NMH} / \mathrm{PBD} / 12.01$.

12. Williamson E, Okpako DT, Evans FJ. Selection, preparation and pharmacological evaluation of plant material. Chichester: Wiley; 1996.

13. Rates SMK. Plants as source of drugs. Toxicon. 2001;39:603-13.

14. Harborne JB. Phytochemical methods: a guide to modern techniques of plant analysis. 3rd ed. London: Chapman and Hall; 1998.

15. Kujur RS, Singh V, Ram M, Yadava HN, Singh KK, Kumari S, et al. Antidiabetic activity and phytochemical screening of crude extract of Stevia rebaudiana in alloxan-induced diabetic rats. Pharmacogn Res. 2010;2:258-63.

16. Maloof AJ, Pandey SK, Neilson G, Milverton E. Selective death of lens epithelial cells using demineralized water and triton X-100 with perfect capsule sealed capsule irrigation: a histological study in rabbit eyes. Arch Ophthalmol. 2005; 123:1378-84.

17. Govindarajan R, Rastogi S, Vijayakumar M, Shirwaikar A, Rawat AK, Mehrotra S, et al. Studies on the antioxidant activities of Desmodium gangeticum. Biol Pharm Bull. 2003;26:1424-7.

18. Mitsuda H, Yuasumoto K, Iwami K. Antioxidation action of indole compounds during the autoxidation of linoleic acid. Eiyo to Shokuryo. 1996;19:210-4.

19. Kyselova Z. Different experimental approaches in modelling cataractogenesis: an overview of selenite-induced nuclear cataract in rats. Interdiscip Toxicol. 2010;3:3-14.

20. Cenedella RJ. Direct chemical measurement of DNA synthesis and net rates of differentiation of rat lens epithelial cells in vivo: applied to the selenium cataract. Exp Eye Res. 1987;44:677-90.

21. Fris $M$, Tessem $M B$, Sather $O$, Midelfart A. Biochemical changes in selenite cataract model measured by high-resolution MAS (1)H NMR spectroscopy. Acta Ophthalmol Scand. 2006;84:684-92.

22. Wang Z, Bunce GE, Hess JL. Selenite and $\mathrm{Ca}^{2+}$ homeostasis in the rat lens: effect on Ca-ATPase and passive $\mathrm{Ca}^{2+}$ transport. Curr Eye Res. 1993;12:213-8.

23. Duncan G, Webb SF, Dawson AP, Bootman MD, Elliott AJ. Calcium regulation in tissue-cultured human and bovine lens epithelial cells. Invest Ophthalmol Vis Sci. 1993;34:2835-42.
24. Duncan G, Williams MR, Raich RA. Calcium, cell signaling and cataract. Prog Ret Eye Res. 1994;13:623-52.

25. Nakajima T, Nakajima E, Fukiage C, Azuma M, Shearer TR. Differential gene expression in the lens epithelial cells from selenite injected rats. Exp Eye Res. 2002;74:231-6.

26. Li WC, Kuszak JR, Dunn K, Wang RR, Ma W, Wang $\mathrm{GM}$, et al. Lens epithelial cell apoptosis appears to be a common cellular basis for non-congenital cataract development in human and animals. J Cell Biol. 1995;130:169-81.

27. Huang LL, Hess JL, Bunce GE. DNA damage, repair and replication in selenite-induced cataract in rat lens. Curr Eye Res. 1990;9:1041-50.

28. Wang KKW, Nath R, Raser KJ, Hajimohammadreza I. Maitotoxin induces calpain activation in SH-SY5Y neuroblastoma cells and cerebrocortical cultures. Arch Biochem Biophys. 1996;331:208-14.

29. David LL, Azuma M, Shearer TR. Cataract and the acceleration of calpain-induced $\beta$-crystallin insolubilization occurring during normal maturation of rat lens. Invest Ophthalmol Vis Sci. 1994;35:785-93.

30. Kupfer C. The conquest of cataract: a global challenge. Trans Ophthal Soc UK. 1984;104:1-10.

31. Harding JJ. Free and protein bound glutathione in normal and cataractous human lenses. Biochem J. 1970;117:957-60.

32. Nishigori H, Lee JW, Iwatsuru M. An animal model for cataract research: cataract formation in developing chick embryo by glucocorticoid. Exp Eye Res. 1983;36:617-21.

33. Ansari NH, Srivastava SK. Role of glutathione in the prevention of cataractogenesis in rat lenses. Curr Eye Res. 1982;2:271-5.

34. Mostafapour MK, Reddy VN. Interactions of glutathione disulfide with lens crystallins. Curr Eye Res. 1982;2:591-6.

35. Jayakumar T, Thomas PA, Geraldine P. In-vitro antioxidant activities of an ethanolic extract of the oyster mushroom, Pleurotus ostreatus. Inn Food Sci Emerg Tech. 2009;10:228-34.

36. Kamalakkannan N, Prince PS. The influence of rutin on the extracellular matrix in streptozotocin-induced diabetic rat kidney. J Pharm Pharmacol. 2006;58:1091-8. 
37. Pragada RR, Rao Ethadi S, Yasodhara B, Praneeth Dasari VS, Mallikarjuna Rao T. In-vitro antioxidant and antibacterial activities of different fractions of Heliotropium indicum L. J Pharm Res. 2012;5(2):1051.

38. Avarachan PJ, Rawal UM. Protein profile is the progressive experimental cataract (selenite model). Indian J Ophthalmol. 1985;33:303-8.

39. Everett GA, Holley RW. Effect of minerals on amino acid incorporation by a rat liver preparation. Biochem Biophys Acta. 1961;46:390.

40. Petry JK. The effect of selenium (Se) on blood serum protein levels in occupational contact. Pregl Lek. 1970;26:552.

41. Horwitz J. $\alpha$-Crystallin can function as a molecular chaperone. Proc Natl Acad Sci USA. 1992;89:10449-53.

42. Hook DWA, Harding JJ. Protection of enzymes by $\alpha$-crystallin acting as a molecular chaperone. Int $\mathrm{J}$ Biol Macromol. 1988;22:295-306.
43. Horwitz J, Bova MP, Ding LL, Haley DA, Stewart PL. Lens $\alpha$-crystallin: function and structure. Eye. 1999;13:403-8.

44. Bloemendal H. Molecular and cellular biology of the eye lens. New York: Wiley; 1981.

45. Horwitz J. Review alpha-crystallin. Exp Eye Res. 2003;2003(76):145-53.

46. Mathias RT, Kistler J, Donaldson P. The lens circulation. J Membr Biol. 2007;216:1-16.

47. Bloemendal $\mathrm{H}$, Zweers A, Vermorken F, Dunia I, Benedetti EL. The plasma membranes of eye lens fibres. Biochemical and structural characterization. Cell Differ. 1972;1:91-106.

48. Gonen T, Walz T. The structure of aquaporins. Q Rev Biophys. 2006;39:361-96. 